\title{
Intercompreensão no ensino de línguas estrangeiras: formação plurilíngue para pré-universitários
}

\author{
Mutual understanding in teaching foreign languages: \\ plurilingual training for pre-university \\ Cristina CAROLA ${ }^{1}$ \\ (Universidade de São Paulo USP)
}

Heloisa ALBUQUERQUE COSTA ${ }^{2}$

(Universidade de São Paulo USP)

\begin{abstract}
RESUMO: Com o recente processo de internacionalização da universidade brasileira, com contratos bilaterais de intercâmbio de estudantes com instituições de ensino de outros países, torna-se necessário refletir sobre uma formação plurilíngue para os estudantes ainda nos níveis anteriores de escolarização e os modos pelos quais ela pode ser alcançada. Mesmo que o jovem não ingresse na universidade, suas competências linguísticas serão requisitadas em outros contextos, como o mercado de trabalho. Baseado nesta realidade, este artigo visa apresentar um modo de contribuir para esta formação, que amplia o repertório linguístico e cultural dos estudantes pré-universitários por meio de uma nova abordagem de ensino de línguas estrangeiras, a Intercompreensão (IC), e a viabilidade da sua inserção no Ensino Médio brasileiro.
\end{abstract}

PALAVRAS-CHAVE: Intercompreensão. Ensino Médio. Formação plurilíngue

\begin{abstract}
Due to late process of Brazilian Universities Internationalization, mutual agreement for students exchange with Educational Institutions from abroad countries, turns out necessary a deep reflection concerning a Multilingual formation for students at a Pre-schooling levels and about which ways it can be reached. Even if a student won't join College level, his linguistic proficiency will be required on a range of segments, say job market for instance. Supported by this actuality, this item urge to display a way to contribute for this ground formation which aims to magnify linguistic and cultural fund of Pre-College students, by means of a new Foreign Language Learning approach, Intercomprehension (IC), and the feasibility of IC insertion at Brazilian High-School Education.
\end{abstract}

KEY WORDS: Intercomprehension. High-School Education. Multilingual formation

\section{INTRODUÇÃO}

Em sociedades tecnológicas e industrializadas, crescem e se diversificam as situações globais de comunicação, reais ou virtuais, para fins comerciais, profissionais ou educacionais, as quais multiplicam as possibilidades de interação e contato entre falantes das mais variadas línguas, de toda parte do mundo. "Estamos imersos em sofisticados processos interativos que transmutam as clássicas categorias de espaço e tempo. A humanidade se descobre reunida num

\footnotetext{
${ }^{1}$ Mestranda do Programa de Pós-graduação de Estudos Linguísticos, Literários e Tradutológicos de Francês da FFLCH-USP. E-mail: cristina.carola@usp.br

2 Professora Doutora do Departamento de Letras Modernas da USP e Coordenadora de Francês do Centro Interdepartamental de Línguas da FFLCH-USP. E-mail: heloisaalbuqcosta@usp.br

(C) Revista Moara, n.42, jul.-dez. 2014, Estudos Linguísticos. ISSN 2358-0658 (Impresso).

Programa de Pós-Graduação em Letras / Universidade Federal do Pará. Todos os direitos reservados.
} 
único lugar [...]”3. A educação, desde os níveis básicos até o universitário, é parte integrante deste cenário e tem como principal objetivo formar cidadãos que sejam capazes de participar, interagir e agir nesse contexto. Um dos meios para isso seria o desenvolvimento de uma competência comunicativa que perpassaria o conhecimento de línguas, seja da língua primeira, "[...] geradora de significação e integradora da organização de mundo e da própria identidade" seja de línguas estrangeiras, como vias de acesso a informações e outras culturas e grupos sociais.

Em contextos multilíngues ${ }^{5}$, o conhecimento de línguas e culturas poderia melhorar a capacidade de os cidadãos comunicarem entre si e ampliar as possibilidades de contato e cooperação recíproca. As instâncias sociais, entre elas a escola, deveriam fomentar atitudes e valores de intercompreensão e alteridade visando o desenvolvimento da competência comunicativa e da tolerância linguística dos indivíduos. A diversidade linguística e cultural, em vez de um obstáculo à comunicação, passa a ser, sob este olhar, uma fonte de enriquecimento do potencial de aprendizagem (COSTE, MOORE, ZARATE, 1998) e de compreensão recíproca. A valorização da diversidade linguística é recente, pois o que se observa, historicamente, é uma política de repressão linguística, que busca priorizar uma variedade linguística e, assim, reforçar a representação social corrente que concebe os indivíduos como fundamentalmente monolíngues (BEACCO, 2007, p.22).

É possível que muitos brasileiros acreditem que o Brasil seja um país monolíngue, onde se fala somente a língua portuguesa. Porém, segundo Oliveira (2008, p.8), "somos um país pluricultural e multilíngue, não só pela atual diversidade de línguas faladas no território [por volta de 210 idiomas], mas ainda pela grande diversidade interna da língua portuguesa [...]". Associado a este multilinguismo interno, que Cavalli et al (2007) denominam "comum e patrimonial", as sociedades atuais, em razão de políticas econômicas e mobilidade profissional provocadas fortemente pela formação de blocos econômicos, como Comunidade Europeia, Mercosul e Nafta, e do surgimento e avanço das TIC (Tecnologias de Informação e Comunicação), se abrem a uma nova diversidade linguística - "se criam novas formas de multilinguismo exógeno, destinadas a se desenvolver mais e mais em função da abertura das fronteiras e da globalização".

Os acordos de mobilidade internacional entre universidades, incluídas as brasileiras, abrem espaço ao multilinguismo também nos contextos universitários, geram novas necessidades de comunicação e interação com o Outro e, por consequência, novas demandas para o ensino de línguas estrangeiras (LE), entre elas o desenvolvimento de competências orais

\footnotetext{
${ }^{3}$ Prefácio de Leonardo Boff para a 10ª edição do livro Reencantar a educação, de Hugo Assmann, 2007.

4 “A linguagem oral, verbal e escrita, representada pela língua materna, ocupa na área o papel de viabilizar a compreensão e o encontro dos discursos utilizados em diferentes esferas da vida social.” (BRASIL, 2000, p.10).

${ }_{5}^{5}$ Neste artigo, usaremos os termos multilinguismo e plurilinguismo conforme J.C. Beacco os usa no Guia para elaboração de políticas linguísticas educativas na Europa (2007): multilinguismo como a presença de línguas em um dado território e plurilinguismo como a competência dos falantes capazes de empregar mais de uma língua. Trecho original: "Cela conduit à distinguer le plurilinguisme comme compétence des locuteurs (capables d'employer plus d'une langue) du multilinguisme comme présence des langues sur un territoire donné : on passe ainsi d'une perspective centrée sur les langues (un Etat peut être dit monolingue ou multilingue) à un autre centrée sur les locuteurs.” (BEACCO, 2007, p.10).

${ }^{6}$ Trecho original: "A côté de ce multilinguisme ordinaire et patrimonial, les sociétés actuelles s'ouvrent à une plus grande diversité linguistique du fait de la mobilité économique et professionnelle accrue : se créent ainsi de nouvelles formes de 'multilinguisme exogène', destinées à se développer de plus en plus du fait de l'ouverture des frontières et de la mondialisation." (CAVALLI et al., 2009, p.4).
} 
e escritas em diversas línguas, não necessariamente todas com o mesmo nível de conhecimento. No caso do Brasil, a formação do MERCOSUL, que reúne Brasil, Argentina, Uruguai e Venezuela, além de outros países associados, tornou mais concretas as situações de interação linguística e cultural. Como consequência, a língua espanhola foi incluída na grade curricular das escolas brasileiras em $2005^{7}$.

A diversificação da oferta de LE nas escolas é um primeiro passo no sentido de atender as novas necessidades de interação, mais complexas na sociedade contemporânea. Mas, além de capacitar o aprendente a usar uma determinada língua estrangeira para fins comunicativos, o aprendizado de LE, se for orientado para tal fim, pode contribuir na formação de um cidadão capaz de respeitar a pluralidade linguística e cultural nas suas mais diversas configurações. A questão que nos colocamos, a partir do cenário brevemente apresentado, é como introduzir uma abordagem plurilíngue no contexto escolar brasileiro, marcado por uma concepção multilíngue (disciplinar) de ensino de línguas estrangeiras.

$\mathrm{Na}$ Europa, os principais documentos que estabelecem parâmetros para o ensino de línguas, como o Quadro Europeu Comum de Referência para as línguas (QECR) (2001) e o Guia de elaboração para políticas linguísticas educativas na Europa $(2003,2007)^{8}$, ao discutirem a diversidade linguística apresentam a noção de plurilinguismo e abordam a necessidade do desenvolvimento de uma competência comunicativa plurilíngue e pluricultural. No Brasil, as políticas educacionais para o ensino de línguas estrangeiras ainda não avançaram neste sentido, visto que o que predomina nas escolas brasileiras ainda é uma abordagem compartimentada (disciplinar), na qual os aprendentes são, ou deveriam ser, levados a desenvolver as competências de expressão e recepção de uma ou mais línguas estrangeiras numa perspectiva multilíngue.

A abordagem plurilinguística ultrapassa esta perspectiva e acentua o facto de que, à medida que a experiência pessoal de um indivíduo no seu contexto cultural se expande, da língua falada em casa para a da sociedade em geral e, depois, para as línguas de outros povos (aprendidas na escola, na universidade ou por experiência direta), essas línguas e culturas não ficam armazenadas em compartimentos mentais rigorosamente separados; pelo contrário, constrói-se uma competência comunicativa, para a qual contribuem todo o conhecimento e toda a experiência das línguas e na qual as línguas se inter-relacionam e interagem. (CONSELHO DA EUROPA, 2001, p.23)

Um dos meios que favorece a construção de uma competência comunicativa plurilíngue e privilegia a questão da interação social é a abordagem plural de ensino de línguas denominada Intercompreensão (IC) que, como define Doyé (2005), é uma forma de comunicação na qual cada pessoa se exprime em sua própria língua e compreende a língua do outro.

Este artigo vai abordar as contribuições que a Intercompreensão poderia oferecer à formação dos estudantes do Ensino Médio brasileiro, a partir da apresentação de projetos em

\footnotetext{
${ }^{7}$ A Lei 11.161, sancionada em agosto de 2005, torna obrigatória a oferta do espanhol no Ensino Médio do país e torna facultativa essa oferta ao Ensino Fundamental de $6^{\circ}$ a $9^{\circ}$ ano a partir de 2010.

${ }^{8}$ Ambos os documentos foram editados pelo Conselho da Europa e são considerados documentos de referência. O Guide pour l'élaboration des politiques linguistiques éducatives en Europe apresenta e discorre sobre um conjunto de princípios e procedimentos para desenvolver e colocar em prática políticas linguísticas.
} 
IC realizados na Europa e de um projeto piloto brasileiro, e destacar pontos de convergência entre esta abordagem plural e conceitos trabalhados nos Parâmetros Curriculares do Ensino Médio (PCNEM) (2000), documento oficial do Ministério da Educação que contém as diretrizes para esse nível de escolarização no Brasil.

\section{Plurilinguismo e abordagens plurais de ensino de línguas estrangeiras}

A noção de plurilinguismo ganhou importância no campo da didática e em contextos institucionais ao longo dos últimos 20 anos, com a publicação de alguns documentos fundadores, tais como o Quadro Europeu Comum de Referência (2001), que dedica um tópico ao desenvolvimento da competência plurilíngue e pluricultural, o Guia para a elaboração de políticas linguísticas educativas na Europa (2003, 2007), que estabelece diretrizes para uma educação plurilíngue, e o Quadro de Referência para as Abordagens Plurais (CARAP) (2007) ${ }^{9}$, que sistematiza as contribuições das abordagens plurais de ensino de línguas estrangeiras.

Segundo o Guia para a elaboração de políticas linguísticas educativas na Europa (2003; 2007, p.18), o plurilinguismo é a capacidade intrínseca de todo falante para empregar e aprender mais de uma língua e um valor educativo, a base para a tolerância linguística, ou seja, para a aceitação positiva da diversidade. Esta capacidade para utilizar mais de uma língua na comunicação/interação social, qual seja o grau de domínio destas línguas, para os mais variados fins, se materializa em um repertório de línguas que podem ser utilizadas. Na primeira versão deste documento (2003), Beacco e Byram postulam que um dos papéis das políticas linguísticas educativas é justamente fazer com que os indivíduos se conscientizem dessa potencialidade, valorizem e tomem consciência de seu repertório linguístico e cultural e, por meio de uma educação plurilíngue, tenham meios de desenvolver esse repertório autonomamente, ao longo da vida, à medida que tomam consciência da complexidade cultural do ambiente em que vivem. A competência plurilíngue seria, então, uma potencialidade de todo indivíduo, que pode ou não ser desenvolvida, dependendo da orientação, multilíngue ou plurilíngue, do ensino de línguas e da complexidade linguística do ambiente.

Para Beacco (2005, p.21), a passagem de uma identidade monolíngue, centrada numa língua identitária, a um modo de ser plurilíngue, "sereno e acolhedor", está ligada à percepção positiva da diversidade linguística que nos cerca. Os sujeitos podem tornar-se capazes de conviver com o Outro em outros meios linguísticos. Essa passagem seria mais ou menos desenvolvida em função do contexto linguístico de cada um, e proporcionada por uma educação plurilíngue.

Essa capacidade de convivência com o Outro é fundamental no momento histórico que vivemos, no qual, como enfatizamos anteriormente, crescem e se diversificam as situações globais de comunicação. Viver nesta "era planetária" exige adaptações dos sujeitos. Morin (2001, p.35) entende que, neste contexto, é necessária a reforma do pensamento para "articular e organizar os conhecimentos e assim reconhecer e conhecer os problemas do mundo". A competência plurilíngue é considerada uma competência transversal, que busca a articulação

9 O CARAP foi publicado em 2007, na versão em francês, e em 2008, em uma versão em espanhol, chamada MAREP (Marco de Referencia para los Enfoques Plurales de las Lenguas y de las Culturas). O documento apresenta um referencial de saberes, saber-ser e saber-fazer suscetível de ser desenvolvido pelas abordagens plurais de ensino de línguas e culturas.

Revista MOARA, n.42, p.99-116, jul./dez. 2014, Estudos Linguísiticos 
dos conhecimentos de línguas e responderia de forma concreta às necessidades de comunicação na "era planetária".

Articular e inter-relacionar conhecimentos seriam condições básicas para uma educação pertinente na "era planetária". Existiria, portanto, segundo Morin (2001), uma inadequação cada vez mais grave entre, "de um lado, os saberes desunidos, divididos, compartimentados e, de outro, as realidades ou problemas cada vez mais multidisciplinares, transversais, multidimensionais, transnacionais, globais e planetários." Para Ferraz (2009, p.150), as relações de aprendizagem precisam ser reconfiguradas e o "currículo, na atualidade, precisa dar conta de paradigmas que tenham em vista a construção coletiva dos sujeitos, partindo tanto da sua diversidade como da sua pluralidade".

Neste contexto, no qual se reconhece o valor político, social e formativo da educação plurilíngue, o esgotamento do modelo de aprendizado por disciplinas (compartimentado), e a necessidade de preparar os sujeitos para viver a pluralidade linguística e cultural da "era planetária”, emerge uma didática própria ao plurilinguismo, que evidencia abordagens plurais de ensino de línguas estrangeiras e busca desenvolver nos sujeitos uma competência comunicativa diferenciada, a competência plurilíngue e pluricultural (COSTE, MOORE E ZARATE, 2009, p. V) definida como

[...][...] competência para comunicar linguageiramente e para interagir culturalmente de um locutor que domina, em diferentes níveis, várias línguas bem como experiências de várias culturas, cabendo a ele gerir o conjunto de seu capital linguístico e cultural. Considera-se que não há sobreposição ou justaposição de competências distintas, mas sim a existência de uma competência plural, complexa, composta e heterogênea, que inclui competências singulares, e mesmo parciais, que compõem o repertório disponível ao ator social. ${ }^{10}$.

Trata-se de uma competência em desequilíbrio ${ }^{11}$ e evolução permanentes, pois as experiências linguísticas e culturais dos sujeitos, dentro e fora da instituição escolar, em momentos diversos de sua existência, mudam sua configuração, a transformam e enriquecem. Esta competência engloba o repertório linguístico à disposição dos sujeitos, autorizando combinações e alternâncias entre línguas, sendo que estas combinações não acontecem aleatoriamente, mas com o intuito de melhorar a comunicação com o outro.

${ }^{10}$ Trecho original: “[...] compétence à communiquer langagièrement et à interagir culturellement possédée par un locuteur qui maîtrise, à des degrés divers, plusieurs langues et a, à des degrés divers, l'expérience de plusieurs cultures, tout en étant à même de gérer l'ensemble de ce capital langagier et culturel. L'option majeure est de considérer qu'il n'y a pas là superposition ou juxtaposition de compétences toujours distinctes, mais bien existence d'une compétence plurielle, complexe, voire composite et bétérogène, qui inclut des compétences singulières, voire partielles, mais qui est une en tant que répertoire disponible pour l'acteur social concernê". O Quadro Europeu Comum de Referência para línguas (2001) reformula sensivelmente esta definição: "A competência plurilíngue e pluricultural é a capacidade para utilizar as línguas para comunicar na interação cultural, na qual o indivíduo, na sua qualidade de ator social, possui proficiência em várias línguas, em diferentes níveis, bem como experiência de várias culturas. Considera-se que não se trata da sobreposição ou da justaposição de competências distintas, mas sim de uma competência complexa ou até compósita à qual o utilizador pode recorrer." (CONSELHO DA EUROPA, 2001, p.231)

11 Desequilíbrio porque o nível de domínio das línguas do repertório pode variar; o perfil de competências em uma língua pode ser diferente da outra. Um indivíduo plurilíngue pode saber ler muito bem em francês e não compreender um falante de francês, mas pode compreender um falante de italiano e não ter domínio da escrita do italiano. 
A concepção de tal conceito [competência plurilíngue e pluricultural] implica ainda uma revisão de antigos paradigmas da didática de línguas (COSTE, MOORE, ZARATE, 2009), entre eles a noção de que se aprende uma língua a partir do zero, a ideia de que as competências a desenvolver têm como modelo ideal o nativo da LE em questão e o equilíbrio entre as competências (de expressão e produção) das LE aprendidas, instituindo outros, tais como a valorização das competências parciais em línguas e dos conhecimentos linguísticos e extralinguísticos anteriores dos aprendentes e a apreensão da noção de competência como capacidade variável e evolutiva, individual e singular (em contraposição ao modelo do nativo), diretamente relacionada às experiências dos sujeitos.

A didática do plurilinguismo (GAJO, 2009) engloba as metodologias referentes às abordagens plurais, assim reunidas por contemplarem duas dimensões: a alternância de línguas e o trabalho comparativo com mais de uma língua.

[...] chama-se abordagem plural toda abordagem que se serve de atividades que implicam, ao mesmo tempo, diversas variedades linguísticas e culturais. Assim sendo, uma abordagem plural se diferencia de uma abordagem singular [compartimentada], na qual o único objeto de atenção é uma língua e uma cultura particular, tomada isoladamente. (CANDELIER, 2008, p.6) ${ }^{12}$

As abordagens plurais - intercompreensão, sensibilização às línguas, didática integrada e abordagem intercultural - se diferenciam das abordagens singulares (compartimentadas) também pela natureza reflexiva do trabalho com as línguas e as culturas, pelo papel que a língua primeira desempenha neste processo e por despertar nos aprendentes a consciência dos próprios modelos de aprendizagem. Dentre elas, neste artigo vamos nos deter nos fundamentos e potencialidades da Intercompreensão.

\section{A abordagem plural: Intercompreensão em línguas aparentadas}

Há muitas definições para intercompreensão, mas a que nos parece mais abrangente e direta é a definição de Degache (2006, p.21) - "compreender a língua do Outro e se fazer compreender na sua língua [língua primeira]" - uma vez que ela aborda dois aspectos essenciais à noção de intercompreensão: a compreensão (escrita e oral) e a interação - esta última compreendida aqui não somente no contexto do encontro de dois ou mais sujeitos, mas no contexto do encontro do sujeito com as línguas, conhecidas ou em fase de descoberta, e do sentido construído neste encontro (CAPUCHO, 2009 apud DEGACHE, 2012). Esse processo de compreensão recíproca, em que cada indivíduo usa a sua língua primeira e não uma língua franca (como o inglês) para se comunicar, é mais bem sucedido quando as línguas dos interlocutores são aparentadas, ou próximas, como as que nascem de uma mesma raiz linguística, pois os indivíduos, mesmo desconhecendo a língua do Outro, podem se apoiar em paridades de ordem lexical, sintática e/ou discursiva entre as línguas, reconhecendo palavras

\footnotetext{
12 Trecho original: "Llamamos "enfoques plurales de las lenguas y culturas" a los enfoques didácticos que ponen en práctica actividades de enseñanza-aprendizaje que implican a la vez, varias (= más de una) variedades lingüisticas y culturales. Oponemos estos enfoques a los que se podrían denominar "enfoques singulares" en los cuales el único objeto de atención de su planteamiento didáctico es una lengua o una cultura particular, tomada aisladamente.” (tradução livre das autoras)
} 
transparentes e construções semelhantes às da própria língua (plural formado com "s" em português e espanhol, por exemplo).

No exemplo a seguir, participantes de uma sessão da plataforma Galanet ${ }^{13}$ negociam, $^{2}$ em um fórum, que nome darão à sessão, que foi realizada entre abril e junho de 2013, cada um usando a sua língua primeira (espanhol, italiano e romeno):

Participante A (16/04/13 20:59)

Me parece muy buena idea. Pero no sé si están todas los idiomas de esta sesión representados en ese título. AYUDA!!!

Participante B (17/04/13 08:35)

¿y Oglindă do monde romance? están las mismas lenguas que en el otro pero se las reconoce mejor. Pongo esta versión, que se puede cambiar si queremos.

Participante C (17/04/13 17:50)

$V$ eo que ya tenemos nombre en la sesión. A mi me gusta

Participante D (17/04/13 18:20)

Manca l'italiano in questo nome. Potrevano cercare uno dove si può inserire al meno le cinque principali lingue: Italiano, Francese, Spagnolo, Portoghese e Romena.

Participante E (17/04/13 20:23)

Ne place mult "Oglinda lumii romani".

Participante B (18/04/13 12:50)

Cierto [Participante $\boldsymbol{B}]$, falta el italiano; ¿qué proponés? [Participante $\boldsymbol{E}$ ] (¿así se escribe tu nombre? ¿con guión en el medio?): la idea es integrar todas las lenguas de la sesión. Tal vez.para representar al rumano podriamos dejar otra palabra, por ejemplo "roman", que es más transparente que oglindă. Y poner "el espejo" en italiano por ejemplo. Algo así como: "El specchio do monde roman". ¿Qué les parece? Podemos cambiar el nombre en cualquier momento, todo bien.

Pode-se observar que, em nenhum momento, em (1a), a compreensão recíproca é prejudicada por questões linguísticas. Os participantes envolvidos negociam o que seria melhor para o grupo, conseguem compreender um ao outro e desenvolver uma tarefa juntos. Há negociação, interação e cumprimento da tarefa que deveriam realizar, ou seja, definir o nome do grupo.

No ensino e aprendizagem de línguas, os professores envolvidos com a abordagem disciplinar, ou seja, línguas ensinadas separadamente umas das outras, podem indagar como as interações realizadas em (1a) poderiam contribuir com a aprendizagem de uma língua estrangeira, principalmente por que, numa perspectiva multilíngue, interferências da língua primeira não são consideradas para a compreensão.

$\mathrm{Na}$ Intercompreensão, o objetivo é ampliar o campo de compreensão de línguas dos aprendentes e, por priorizar a compreensão, esta abordagem não prevê o conhecimento das línguas aparentadas no sentido de conhecer bem, "pode-se visar um conhecimento mais modesto, limitado e, desta maneira, mais fácil de adquirir" (BLANCHE-BENVENISTE e VALLI, 1997:34).

Mais que aprender aspectos linguísticos pontuais das línguas aparentadas à sua língua primeira, com a abordagem intercompreensiva o aprendente é levado a se valer da proximidade inter-linguística entre a língua desconhecida e a sua língua, de seus conhecimentos prévios

13 A Galanet é uma plataforma europeia que tem por finalidade estimular e promover interações plurilíngues _www.galanet.eu 
(repertório linguístico, por exemplo), de suas competências linguísticas e capacidades comunicacionais, construídas ao longo de sua formação como falante de uma língua, para testar suas intuições sobre as línguas estrangeiras e, assim, compreender o Outro.

$\mathrm{Na}$ Intercompreensão, a prioridade dada ao desenvolvimento das habilidades receptivas (compreensão escrita e oral) não é arbitrária. Degache (2012, p.12) enumera três categorias de argumentos nos quais se baseiam as abordagens metodológicas que priorizam as habilidades receptivas em geral:

- argumento ontogenético, ligado ao desenvolvimento do indivíduo ("a compreensão precede a produção" seja na aquisição da língua primeira ou da língua estrangeira, "em particular em contexto social");

- argumento cognitivo: "em geral compreendemos melhor do que falamos";

- argumento "aquisicional": "para aprender línguas com sucesso é preciso a exposição a mensagens compreensíveis na língua-alvo, e isto, em situações verdadeiras de comunicação".

No caso de uma abordagem disciplinar de línguas, a compreensão escrita serviria como input para o desenvolvimento das outras três competências (compreensão oral, produção oral e produção escrita). A IC e as outras abordagens plurais também se servem deste input, que pode ou não evoluir em direção às outras competências de uma dada língua.

É também nesta perspectiva que o conceito de competência parcial numa dada língua é significativo: não se trata apenas de nos darmos por satisfeitos, por razões de princípio ou de pragmatismo, com o desenvolvimento de um domínio limitado ou compartimentado de uma língua estrangeira, mas sim de encarar esta proficiência imperfeita num dado momento - como fazendo parte de uma competência plurilíngue que a enriquece. Deve também ser salientado que esta competência 'parcial', que é uma parte de uma competência múltipla, é, ao mesmo tempo, uma competência funcional relacionada com um objetivo estabelecido bem delimitado. (CONSELHO DA EUROPA, 2001, p.190)

Para Castellotti e Moore (2002, p.20), a IC tem um objetivo mais amplo, que é o desenvolvimento e a construção de competências transversais, como a competência plurilíngue e pluricultural, que podem ser reativadas quaisquer que sejam as línguas aprendidas, numa perspectiva funcional. Daí a importância que se dá, em IC, ao trabalho com as estratégias de compreensão, sejam elas cognitivas (transferência, inferência, atividade metalinguística), metacognitivas (dizem respeito à capacidade que toda pessoa tem de poder refletir sobre seu próprio processo mental) ou sócio-afetivas (como a negociação de sentido numa interação) (O’MALLEY e CHAMOT, 1990 apud DEGACHE, 2005, 2012). Com o desenvolvimento das estratégias apropriadas à compreensão escrita, o aprendente pode adotar conscientemente uma linha específica de ação a fim de atender as "exigências de comunicação em contexto e a completar com êxito a tarefa em causa, da forma mais exaustiva ou mais econômica, segundo os seus objetivos pessoais" (CONSELHO DA EUROPA, 2001, p.90).

Para Chavagne, a prática da intercompreensão não interfere nas atividades de ensino de línguas tomadas em uma perspectiva multilíngue. 
Elas teriam, ao contrário, creio eu, muito mais para se beneficiar com o simples avanço da Intercompreensão. A Intercompreensão se apresentando principalmente como um primeiro passo essencial em direção à língua do Outro, em direção à cultura do Outro, em direção ao Outro propriamente dito, um primeiro passo recíproco, cheio de sentidos, que não obriga a dar um segundo, mas que não impede, de nenhum modo, de fazê-lo. (CHAVAGNE, 2006, p.5)

Segundo Coste (2011, p.188), todo aluno deveria ter a experiência, entre outras, da Intercompreensão, por conta da relação que a abordagem propõe com a linguagem, a pluralidade de línguas e a alteridade. "Haveria, sem dúvida, muito a ganhar ao incluir no currículo este componente particular [diversidade de contatos com línguas] visando assegurar uma cultura de aprendizagem de línguas [...].”

\subsection{Intercompreensão no Ensino Médio}

Apesar de as pesquisas em IC se desenvolverem, quase exclusivamente, em contexto universitário, o qual tem demandado uma formação cada vez mais plurilíngue, essa abordagem pode e deve (COSTE, 2011, p.187) ser inserida desde os níveis iniciais de escolarização (na realidade brasileira, seriam os ensinos Fundamental ${ }^{14}$ e Médio), devido à sua relação com a linguagem e com a pluralidade de línguas, mas também, em sua dinâmica de relacionamento com a alteridade. Espera-se que a experiência da intercompreensão, além de formar um repertório plurilíngue e desenvolver as capacidades para "aprender a aprender" "15, torne os indivíduos mais confiantes nas próprias capacidades e nas formas de apreensão da linguagem por meio da diversidade de contatos com as línguas (COSTE, 2011, p. 188). Autoconfiança e "flexibilidade adaptativa" (ASSMANN, 2007, p.22), isto é, manter-se em estado permanente de aprendizagem, são características requisitadas aos cidadãos do mundo contemporâneo.

É para viver neste mundo que nossas crianças e jovens devem ser formados, e a instituição escolar precisaria criar meios para responder a esta necessidade em todas as etapas de escolarização. Consideramos que a Intercompreensão, ao trazer a possibilidade de interação entre línguas e culturas e desenvolver competências transversais, que podem ser reativadas quaisquer que sejam as línguas aprendidas, seria um dos meios de prepará-los, no que se refere às questões da linguagem.

Mas a integração do conceito de intercompreensão ao ensino, segundo Escudé e Janin (2010), ainda esbarra em dois obstáculos: a organização disciplinar dos sistemas educativos ('savoirs étanches') e a ideologia que uma única língua seria a solução para os problemas de comunicação do mundo globalizado. Obstáculos que, para estes autores, seriam vencidos com pedagogias novas e eficazes e ao mostrar que "a IC pode fazer evoluir positivamente as estruturas educativas para nelas integrar o plurilinguismo e sua ética de respeito mútuo”. Em

\footnotetext{
${ }^{14}$ Cabe destacar a iniciativa da professora Selma Alas Martins, da Universidade Federal do Rio Grande do Norte, que mantém, desde 2011, um projeto de inserção curricular da Intercompreensão no Ensino Fundamental II das escolas públicas municipais de Natal (RN).

15 "Apprendre à apprendre les langues, voici la finalité de l'intercompréhension: pour les citoyens du monde de demain, c'est là qu'elle montre son efficacité, et sans doute aussi, sa nécessité." (JANIN, Pierre. "L'intercompréhension entre langues apparentées" Délégation générale à la langue française et aux langues de France)
} 
relação à organização disciplinar dos sistemas educativos em geral, Assmann (1997, p.33) afirma que

É preciso substituir a pedagogia das certezas e dos saberes pré-fixados por uma pedagogia da pergunta, do melhoramento das perguntas e do 'acessamento' de informações. Em suma, por uma pedagogia da complexidade, que saiba trabalhar com conceitos transversáteis, abertos para a surpresa e o imprevisto.

Villalón et al (2011), ao tratarem da inserção da Intercompreensão em contexto universitário no Chile, também apontam a necessidade de se abandonar a "matriz curricular minimalista" para elaborar um novo currículo, "que permita acolher a complexidade da realidade das necessidades comunicacionais". Os autores citam ainda que as autoridades universitárias chilenas vêm reclamando das dificuldades dos alunos ingressantes nas competências de compreensão escrita e produção oral.

No contexto universitário brasileiro, há uma crescente demanda para o desenvolvimento de competências para a leitura de textos científicos em línguas estrangeiras de diferentes áreas do conhecimento, o que, teoricamente, deveria ter sido trabalhado no Ensino Médio, uma vez que os PCNEM consideram primordial o desenvolvimento da competência de leitura/interpretação em LE. Esta demanda nos mostra que o repertório linguístico da maioria dos jovens que ingressa na universidade, principalmente os egressos da rede pública de ensino, está muito aquém das reais necessidades que eles enfrentam na universidade, instituição que, no Brasil, vive um franco processo de internacionalização, ratificando a importância do conhecimento de línguas estrangeiras.

Uma das causas desse repertório deficiente dos jovens poderia ser a forma de organização da grade curricular, que no Brasil geralmente ${ }^{16}$ oferece apenas uma língua estrangeira aos aprendentes, o inglês, ignorando outras possíveis necessidades da comunidade - escolas em regiões de fronteira com outros países, imigração/ colônia de imigrantes ou a presença de outros povos, como os indígenas.

Em relação à diversificação da oferta de línguas estrangeiras, os PCNEM advertem que ao inserir mais línguas estrangeiras na grade curricular, "o Ensino Médio passe a organizar seus cursos de Línguas objetivando tornar-se algo útil e significativo, em vez de representar apenas uma disciplina a mais na grade curricular" (BRASIL, 2000, p.27-28). Isso significaria trazer para o cotidiano da sala de aula atividades que contemplassem, além de conteúdos linguísticos, aspectos culturais e formativos, como a alteridade. Mas a priorização dos objetivos linguísticos pode deixar indefinidos para o aprendente os objetivos educacionais e culturais (importância para a vida e a construção da cidadania do aprendente, por exemplo) inerentes ao ensino das línguas estrangeiras. As Orientações Curriculares para o Ensino Médio (2006, p.89) chamam esta situação de "conflito de objetivos".

Diversificar a oferta de LE considerando os objetivos educacionais e linguísticos do aprendizado de línguas poderia ser uma maneira de preparar melhor esse jovem, oferecendo a ele a possibilidade de uma formação plurilíngue, de caráter interdisciplinar (projetos que envolvessem as línguas estrangeiras e a língua primeira), capaz de desenvolver competências

\footnotetext{
${ }^{16}$ Desde 2005, o espanhol passou a ser oferecido, em caráter obrigatório, no EM. O que ocorre muitas vezes é o oferecimento em caráter optativo e, algumas vezes, os jovens não têm aulas por falta de professores.
} 
transversais e de tornar o jovem mais preparado para ingressar na universidade e/ou no mercado de trabalho.

Além da oferta de línguas, outro fator relevante para a formação plurilíngue desses jovens é a maneira como as LE seriam aprendidas: de forma desarticulada, por meio de abordagens compartimentadas, nas quais as línguas são aprendidas do "zero" (sem consideração dos conhecimentos prévios), o modelo ideal é o falante nativo e as "interferências" da língua primeira na aprendizagem são indesejáveis; ou de maneira articulada, por meio de abordagens plurais que valorizam a relação entre as línguas estrangeiras e entre elas e a língua primeira.

Sem articulação entre as línguas, todo esforço destinado a aumentar o número de línguas aprendidas por um mesmo indivíduo na educação formal se chocará imediatamente com os limites em termos de capacidade de aprendizagem e espaço nos currículos, limites que a sinergia posta em prática pelos enfoques plurais permite $\operatorname{ampliar}^{17}$ (CANDELIER et al, 2008, p.8)

A questão que se coloca é se podemos optar pela Intercompreensão para formar o estudante do Ensino Médio brasileiro e quais seriam os benefícios desta situação de ensinoaprendizagem no sentido de amenizar o referido "conflito de objetivos" presente no aprendizado de uma língua estrangeira. Quando mencionamos a introdução da Intercompreensão no EM significa agregar à atual proposta de ensino de línguas uma outra, que aponta para um trabalho que articula objetivos linguísticos, culturais e educacionais. Assim, "busca-se a formação de indivíduos, o que inclui o desenvolvimento de consciência social, criatividade, mente aberta para conhecimentos novos, enfim, uma reforma na maneira de pensar e ver o mundo." (MINISTÉRIO DA EDUCAÇÃO, 2006, p. 90).

O projeto piloto de intercompreensão, realizado em 2013, em uma escola de Ensino Médio do estado de São Paulo, nos mostrou que a proposta de trazer a IC para o contexto do EM é perfeitamente viável. Foram realizados encontros presenciais com os alunos, nos quais eram propostas atividades de leitura em cinco línguas românicas (espanhol, francês, italiano, romeno e catalão), sempre observando a alternância de línguas e o trabalho comparativo com mais de uma língua. O objetivo principal do projeto era oferecer meios para que os participantes desenvolvessem sua competência leitora plurilíngue, visando facilitar sua inserção na universidade, no mercado de trabalho e na vida social adulta, principalmente no atual cenário de interação e mobilidade.

Os exercícios propostos exploravam o uso de estratégias de leitura, tais como o reconhecimento global de palavras, o pareamento de elementos cognatos (transparência/ transferência) e a inferência, e a atividade metalinguística. O que observarmos na produção dos participantes é um "despertar" para as estratégias de leitura - "Aprendi a procurar palavras que sejam parecidas com o português, observar as imagens e outras informações que rodeiam o texto, entendendo o contexto." (R.M. 16 anos); "Sim porque aprendi técnicas de como ler um texto em língua desconbecida." (V.R. 16 anos) - o que não significa que o grupo passou a empregá-las com eficiência. Algumas

\footnotetext{
17 Trecho original: "Sin articulación entre las lenguas, todo esfuerzo destinado a aumentar el numero de lenguas aprendidas por una misma persona-aprendiz en el marco de la educación formal se chocará inmediatamente con los límites en términos a la vez de capacidad de aprendizaje y de espacio en los curriculos, limites que la sinergia puesta en práctica por los enfoques plurales permite de ampliar."
} 
das produções dos participantes indicaram o uso de estratégias cognitivas, mais precisamente o reconhecimento global de palavras e o pareamento de elementos cognatos (transparência/ transferência), ou seja, os participantes procuram na língua primeira palavras que se pareçam com aquela cujo significado desconhecem em vez de considerar os indícios que estão no texto para inferir seu significado. O trabalho realizado fez com que os jovens "descobrissem" as línguas românicas e suscitou neles um sentimento de confiança em relação à leitura de textos em línguas nunca estudadas - "Eu aprendi as principais diferenças e as características das línguas latinas, românicas. Isso é importante, pois com o bábito da leitura, acabei conseguindo identificar características que antes eu não percebia, principalmente na lingua italiana. Com isso, com certeza posso ler alguns textos com menos dificuldade do que antes." (R.S. 16 anos); "Passei a entender o contexto [...], comparar, usar palavras transparentes.” (C.M. 16 anos).

Nosso projeto piloto propôs a realização de um curso de Leitura Plurilíngue, oferecido fora da grade curricular. Entretanto há diversas formas de inserção da Intercompreensão no EM. Por exemplo, como um projeto complementar dentro de um curso curricular de língua estrangeira, como mostra uma experiência realizada entre 2001 e 2002, em Portugal (ANDRADE et al, 2009), com uma turma de latim do Ensino Secundário, na qual foram trabalhados textos em diferentes línguas em momentos específicos do programa da disciplina. As atividades, segundo as pesquisadoras, influenciaram positivamente as atitudes dos participantes em relação à compreensão das línguas objeto de estudo escolar (que neste projeto não se limitaram às línguas românicas, foram incluídos textos em alemão, sueco e inglês, por exemplo); e à (im)possibilidade de se compreender uma língua nunca antes estudada.

Apesar do caráter pontual das atividades implementadas, no contexto do desenvolvimento da disciplina ao longo dos dois anos letivos, foi possível confirmar a importância do Projeto Plurilíngue no desenvolvimento das competências das alunas para lidar com diferentes línguas. Este impacto terá sido mais significativo no campo das atitudes face às línguas, à comunicação/compreensão e à aprendizagem, mas os dados do estudo indiciam que este tipo de trabalho, se tiver presença mais assídua nas aulas de língua, poderá influenciar também a aprendizagem, quer da língua-alvo da disciplina, quer de elementos de outras línguas que irão enriquecer o repertório linguístico-comunicativo dos aprendentes e, assim, dotá-los de maior variedade de instrumentos a que recorrer em situações de compreensão/comunicação futuras. (ANDRADE et al, 2009, p.295)

Outro estudo, nos mesmos moldes, ou seja, a inserção de um percurso em IC no programa de um curso de línguas, foi realizado em uma escola de Ensino Médio na Argentina, em 2008 (GRIOT, 2008). O autor desse estudo trabalhou com duas propostas a partir da inserção de uma sessão plurilíngue (Galanet) no curso de francês (FLE): a sessão plurilíngue como suporte a exercícios de francês e como apoio a tarefas de avaliação em francês. Segundo Griot, "a experiência Galanet não poderia ter sido mais enriquecedora em seu aspecto humano". Foi a experiência intercultural mais valorizada pelos estudantes, por seus professores e pela própria instituição de ensino. "Mesmo se alguns alunos não fizeram ligação entre a experiência [Galanet] e os benefícios que eles poderiam colher disso em sua carreira universitária, outros mencionaram vantagens para a compreensão de textos [em línguas] 
estrangeiros.” (GRIOT, 2008, p.49).$^{18}$ Esta afirmação do autor do estudo, evidencia o referido "conflito de objetivos" da área: os alunos nem sempre conseguem reconhecer imediatamente os benefícios de uma experiência enriquecedora como essa, por conta de sua dimensão educativa.

Além de trazer benefícios, mesmo incluída pontualmente nos cursos de línguas, como vimos anteriormente, a Intercompreensão pode ser "objeto" de um curso à parte na grade curricular. Este é o caso de um projeto realizado em Barcelona, na Espanha, (MARGUERITTE, 2011), em 2010, com jovens voluntários de um centro de idiomas, que associou aulas de IC e a participação em uma sessão plurilíngue no Galanet a fim de trabalhar as competências de compreensão escrita e oral dos jovens em quatro línguas românicas e as competências em contexto de interação plurilíngue. Além de desenvolver conhecimentos sobre as línguas estudadas e estratégias de aprendizagem que os adolescentes pudessem reutilizar de forma autônoma em seus cursos de línguas, o curso buscou abordar as atitudes face à aprendizagem de línguas. A IC mostra que é possível, e usando conhecimentos prévios do próprio estudante, o que os torna mais confiantes diante do texto em língua estrangeira. A "simples" percepção da relação de parentesco entre as línguas, que na abordagem segmentada não é estimulada por conta dos "contágios", leva a "relativizar a percepção de dificuldades de aprendizagem das línguas e tem impacto direto na motivação do aprendente" "19 (PISHVA, THAMIN, 2012, p.261).

Segundo Margueritte, os adolescentes compreenderam que há uma maneira de interagir com um interlocutor que não fala a língua deles: "Intentar hablar lento para que comprenda mejor tu mensaje, utilizar un lenguaje más formal, por ejemplo decir adolescente en vez, de chaval. [...] Escribir sin faltas y correctamente y repetir de otra manera si no te entiende." 20 (MARGUERITTE, 2011, p.65); e que "a Intercompreensão é útil para a apreensão geral da vida, para além do ensino de língua e do ambiente escolar": "la intercomprensión sirve para todos los aspectos de la vida, ya sea para estudiar idiomas u otras cosas."21 (MARGUERITTE, 2011, p.96). A "conclusão" a que chega este participante do curso em Barcelona, a ideia que ela encerra, do benefício estendido para além da escola, é a chave para a resolução do "conflito de objetivos" no ensino de línguas e um indicativo de que a IC é realmente um caminho promissor, principalmente no aspecto educacional, formativo do ensino de línguas.

Outra experiência nesta mesma linha, de considerar a IC um "objeto" de estudo, se deu na Itália (NIELFI, 2011), com estudantes de francês e espanhol de uma escola secundária ('liceo linguistico'). Foram realizados dois cursos com formatos diferentes: o primeiro deles híbrido, com aulas presenciais dedicadas à comparação entre as línguas e participação em uma sessão plurilíngue na Galanet; e o segundo se deu quase exclusivamente via Galanet. A pesquisa

\footnotetext{
18 Trecho original: "Même si quelques élèves ne font pas le lien entre l'expérience et les bénéfices qu'ils pourraient en tirer dans leur carrière universitaire, d'autres parlent d'avantages pour la compréhension de textes étrangers." (GRIOT, 2008, p.49)

19 Trecho original: "relativiser la perception de difficultés d'apprentissage des langues et a un impact direct sur la motivation de l'apprenant” (Pishva e Thamin).

20 "Tentar falar lentamente para que compreenda melhor tua mensagem, utilizar uma linguagem mais formal, por exemplo, dizer 'adolescente' em vez de 'chaval' [gíria] [...] Escrever sem erros e corretamente e repetir de outra maneira se não te entendem" (tradução livre das autoras)

21 "A Intercompreensão serve para todos os aspectos da vida, seja para estudar idiomas ou outras coisas" (tradução livre das autoras)
} 
visava experimentar a didática de intercompreensão e observar uma situação de aprendizagem colaborativa e interação plurilíngue.

O ponto forte desta experiência, segundo a pesquisadora, foi o desenvolvimento de competências em contexto de interação plurilíngue - habilidades de interação escrita em italiano (língua primeira) e em línguas estrangeiras (francês e/ou espanhol). A participação nos fóruns da sessão plurilíngue fez com que os alunos passassem a prestar mais atenção aos articuladores textuais e ao tipo de registro textual; enriqueceu seus conhecimentos das línguas estudadas; os colocou em contato com novas línguas e participantes de países muito distantes; e melhorou seu desempenho com as TIC.

A diversificação linguística oferecida na Galanet, que compreende línguas que geralmente não são oferecidas nas escolas italianas, como português, romeno, catalão... traz significativas perspectivas formativas: basta pensar em como o campo linguístico pode ser enriquecido por conteúdos sociais, literários, histórico-filosófico e artísticos. (NIELFI, 2010, p.7) 22

Em Portugal, a experiência com a IC e os pré-universitários (12 ano) também incluiu encontros presenciais e participação em uma sessão plurilíngue na Galanet. O que diferencia este estudo (CARRINGTON, 2011) dos demais, é seu objetivo: verificar se a experiência de Intercompreensão pode repercutir nos conhecimentos em Português LM [língua primeira] e na relação sócio-afectiva com a LM. Segundo a autora do estudo, o contato com as línguas românicas [LR] na plataforma

[...] parece ter potenciado a relação afetiva dos aprendentes com a sua LM, numa clara valorização identitária e afectiva, a que já chamámos 'passerelle afectiva' das LR para a LM. Simultaneamente, esse contacto plurilingue permitiu reconhecer o papel e o estatuto da LM no contacto com outras línguas, tendo-se, na nossa opinião, valorizado o conhecimento do funcionamento da LM no acesso aos dados verbais das restantes línguas ('passerelle cognitiva' da LM para as LR). (CARRINGTON, 2011, p.121)

A nossa experiência com o projeto piloto e os resultados positivos dos estudos com a IC no contexto do ensino médio, ou nível secundário, em outros países, confirmam as contribuições que a IC tem a dar, principalmente, à dimensão educativa do ensino de línguas estrangeiras no contexto do EM brasileiro. Para Coste (2011, p.187) é a perspectiva educativa que se sobressai cada vez mais nas experiências de Intercompreensão. De acordo com o texto dos PCNEM,

[...] torna-se fundamental conferir ao ensino escolar de línguas estrangeiras um caráter que, além de capacitar o aluno a compreender e a produzir enunciados corretos no novo idioma, propicie ao aprendiz a possibilidade de atingir um nível de competência linguística capaz de permitir-lhe acesso a informações de vários tipos,

\footnotetext{
22 Trecho original: 'La diversificazione linguistica che Galanet offre, con l'ampliamento a lingue generalmente non presenti nell'offerta formativa dei licei italiani, come il portoghese, il rumeno, il catalano... implica notevoli prospettive formative: basti pensare a come l'ambito linguistico possa arricchirsi di contenuti sociali, letterari, storico-filosofici e artistici.” (NIELFI, 2010, p.7)
} 
ao mesmo tempo em que contribua para a sua formação geral enquanto cidadão. (BRASIL, 2000, p.26)

Ao se trabalhar as línguas próximas articuladamente se estende o horizonte de comunicação do aprendente e se reforça o respeito à diversidade de construções simbólicas. Ao permitir que os aprendentes usem seus conhecimentos linguísticos, inclusive os da língua primeira, para compreender as línguas estrangeiras, se atribui nova, e positiva, dimensão de valor aos conhecimentos da língua primeira e se promovem experiências bem-sucedidas que desenvolvem a confiança do aprendente. Em relação às interações, o aprendente observa que não necessariamente precisa de uma língua franca para se comunicar, principalmente com falantes de línguas aparentadas.

\section{CONSIDERAÇÕES FINAIS}

Apesar de suas bases terem sido lançadas na década de 1970, a Intercompreensão ainda não conhece uma inserção curricular significativa, principalmente nos níveis fundamentais de escolarização, mesmo que as pesquisas atestem suas contribuições e seu potencial para a formação plurilíngue dos aprendentes. A cultura da aprendizagem gradual e singular, além de outros paradigmas do ensino de línguas estrangeiras, e um dos mais conflitantes com a IC é a presença da língua primeira (materna) do aprendente como ponto de apoio, como portal para as outras línguas, pode explicar essa dificuldade de inserção da IC nos currículos. A formação do professor de línguas estrangeiras, baseada nos "velhos" paradigmas, também dificulta a sua inserção.

Como pudemos observar em nosso projeto experimental e nos estudos destacados neste artigo, a experiência de intercompreensão - a que todos deveriam poder ter acesso pela relação que propõe com a linguagem, a diversidade e a alteridade - não precisa do mesmo espaço reservado às línguas estrangeiras ditas essenciais na grade curricular. Em todas as aulas de línguas, primeira ou estrangeira, é possível oferecer esta "experiência" ao aprendente; e não só nas aulas de línguas, pois assim como a linguagem, a IC é transdisciplinar e pode servir a projetos interdisciplinares como meio de acesso a informações de vários tipos e fontes.

O professor e a escola podem se apropriar do potencial da IC para a educação em línguas estrangeiras (dimensões linguística e educacional) e explorá-lo conforme o projeto de formação dos estudantes, que no Ensino Médio, inclui o desenvolvimento de consciência social, criatividade e mente aberta para conhecimentos novos. Destacamos o Ensino Médio por ter sido o contexto no qual experienciamos a IC, e o nível de escolaridade mais próximo da universidade e do mercado de trabalho, contextos nos quais a diversidade linguística e cultural se faz cada vez mais presente.

Por fim, ao se ler os documentos que parametrizam o EM brasileiro, percebe-se que há muitos pontos convergentes entre os princípios da IC e a concepção de ensino de línguas estrangeiras idealizada nos documentos, como os que foram apontados neste artigo. $\mathrm{O}$ que nos parece faltar são mais experiências com a Intercompreensão em escolas brasileiras, em todos os níveis de escolaridade, em variados contextos (fronteiras, colônia de imigrantes), para que possamos compreender os efeitos desta abordagem nos nossos estudantes. 


\section{REFERÊNCIAS}

ANDRADE, A.; MELO-PFEIFER, S.; SANTOS, L. Que lugar para a intercompreensão em contextos de aprendizagem formal? Propostas de inserção curricular de abordagens plurilíngues. In: ARAÚJO E SÁ, M. H. al (org.). A Intercompreensão em Línguas Românicas: conceitos, práticas, formação. Aveiro, Po: CIDTFF - Departamento de Didáctica e Tecnologia Educativa, Universidade de Aveiro, 2009.

ASSMANN, Hugo. Reencantar a educação: rumo à sociedade aprendente. 10. ed. Petrópolis, Rj: Vozes, 2007.

BEACCO, J. C. Langue et répertoire des langues : le plurilinguisme comme manière d'être en Europe. Strasbourg, Fr : Conseil de l'Europe, DG IV, 2005.

BEACCO, J. C. (Org.) De la diversité linguistique à l'éducation plurilingue: Guide pour l'élaboration des politiques linguistiques éducatives en Europe. Division des Politiques linguistiques. Strasbourg, Fr : Conseil de l’Europe, 2007. Version intégrale.

BEACCO, J. C. ; BYRAM, M. (Org.) De la diversité linguistique à l'éducation plurilingue: Guide pour l'élaboration des politiques linguistiques éducatives en Europe. Division des Politiques linguistiques Strasbourg, Fr: Conseil de l'Europe, 2003. Version intégrale.

BRASIL. Secretaria de Educação Básica. Parâmetros Curriculares Nacionais para o Ensino Médio. Brasília: Secretaria de Educação Básica, 2000.

BLANCHE-BENVENISTE, C. VALLI, A. (Org). Une grammaire pour lire en quatre langues In: L'intercompréhension: le cas de les langues romanes. Le Français dans le monde: recherches et applications. Paris: Hachette, 1997, p. 33-37.

CANDELIER, M. et al (Coord.) . Cadre de Référence pour les Approches Plurielles. Centre européen pour les langues vivantes. Conseil de l'Europe, 2007.

CARRINGTON, M. A Língua Materna Revisitada através de práticas de Intercompreensão. Dissertação [Mestrado] - Universidade de Aveiro, 2011.

CASTELLOTTI; V. MOORE, D. Répresentations sociales des langues et enseignements. Guide pour l'élaboration des politiques linguistiques éducatives em Europe : De la diversité linguistique à l'éducation plurilingue : Etude de référence. Strasbourg : Conseil de l'Europe, 2002.

CAVALLI, M. COSTE, D. CRISAN, A. VEN, P. H. L'éducation plurilingue et interculturelle comme projet. Strasbourg : Conseil de l'Europe, DG IV / EDU / LANG, 2009. 
CHAVAGNE, J. P. A intercompreensão entre línguas vizinhas. In: Jornada da Sociedade Francesa de Tradução, 2006, Lyon: Ucly.

CONSELHO DA EUROPA. Quadro Europeu Comum de Referência para as línguas. Porto : Asa Editores, 2001.

COSTE, Daniel. Leitura e competência comunicativa. In: O Texto: leitura e escrita. Organização e revisão técnica da tradução: Charlotte Galves, Eni P. Orlandi, Paulo Otoni. 3. ed., rev. Campinas-SP : Pontes, 2002.

COSTE, Daniel. Plurilinguisme et Intercompréhension. In: ÁLVAREZ, Dolores, CHARDENET, Patrick Chardenet, TOST, Manuel. (Dir.). L'intercompréhension et les nouveaux défis pour les langues romanes. Union Latine. Agence universitaire de la Francophonie, Paris : Agence universitaire de la Francophonie, 2011. p. 179-189.

COSTE, D. MOORE, D. ZARATE, G. Compétence plurilingue et pluriculturelle : Vers un Cadre Européen Commun de référence pour l'enseignement et l'apprentissage des langues vivantes: études préparatoires. Version révisée. Strasbourg : Conseil de l’Europe, 2009.

DEGACHE, C. Didática das línguas e didática do plurilinguismo: o lugar da intercompreensão. São Paulo: Curso de Pós-graduação, Universidade, 2012.

DOYE, Peter. Intercomprehension. Strasbourg: Council of Europe, Language Policy Division, DG IV, 2005. Disponível em: <http://www.coe.int/t/dg4/linguistic/Source/Doye\%20EN.pdf>. Acesso em: 12/02/2014.

FERRAZ, O. Tecendo saberes na rede: o Moodle como espaço significativo de leitura e escrita. In: ALVES, L. BARROS, D. OKADA, A. (Org.) Moodle: estratégias pedagógicas e estudo de caso. Salvador: EDUNEB, 2009.p. 143-164.

GAJO, L. De la DNL à la DdNL. Principes de classe et formation des enseignants. In : Enseignants de DNL et de LV: à armes égales? Université de Génève 4/2009.

GRIOT, P. Intercompréhension en langues romanes et FLE: Galanet comme support d'enseignement-apprentissage. Mémoire de Master 2 FLE professionnel, U. Grenoble 3. Disponível em : <http://www.galanet.eu/publication/fichiers/Griot2008.pdf > . Acesso em: 15/08/2013.

MARGUERITTE, A. L'insertion curriculaire de l'intercompréhension dans l'enseignement de langues pour un public d'adolescents. Dissertação [Mestrado] Universidade Autônoma de Barcelona, 2011. 
MINISTÉRIO DA EDUCAÇÃO. Secretaria de Educação Básica. Orientações Curriculares para o Ensino Médio. Linguagens, códigos e suas tecnologias. Brasília: Secretaria de Educação Básica, 2006, 239 p. v. 1.

MORIN, Edgar. Os sete saberes necessários à educação do futuro. 4. ed. São Paulo: Cortez; Brasília, DF: UNESCO, 2001.

NIELFI, C. Verso l'educazione plurilingue: la via dell'intercomprensione. LEND, Lingua e nuova didattica, n.2, avril 2010.

OLIVEIRA, Gilvan Müller de. Plurilinguismo no Brasil. Instituto de Investigação e Desenvolvimento em Política Linguística. Representação da Unesco no Brasil. Disponível em : $<$ http://unesdoc.unesco.org/images/0016/001611/161167por.pdf $>$. Acesso em: 02/02/2014.

PISHVA, Yasmin; THAMIN, Nathalie. Pratiques de formation aux approches plurielles: approche réflexive et intercompréhension. In Redinter-Intercompreensão. Investigação sobre metodologia de ensino de intercompreensão. 2012, p. 249-267.

VILLALÓN, C.; TASSARA, G.; MORENO F., P. La intercomprensión entre lenguas latinas en las políticas educacionales: el caso de Chile. In: ÁLVAREZ, Dolores ; CHARDENET, Patrick; TOST, Manuel, (Dir.). L'intercompréhension et les nouveaux défis pour les langues romanes. Paris: Union Latine, Agence universitaire de la Francophonie, 2011. p. 191-209.

Recebido em 06/05/2014

Aprovado em 04/11/2014 